\title{
Proteïnes marginals a Mallorca: cuinar tortugues, eriçons i rates de s'Albufera Antoni Contreras Mas
}

\section{Proteïnes marginals a Mallorca}

Una de les característiques principals de l'alimentació humana és la capacitat d'adaptació a qualsevol casta de dieta. L'abastament dels seus elements fonamentals pot partir de gairebé qualsevol nivell de l'escala tròfica. L'home és capaç de treure profit dels graons més baixos o dels més alts d'aquesta escala, cercant els seus principis fonamentals en aliments tan distints i diferenciats com els fongs o els mamífers més evolucionats; sense descartar-ne, fins i tot, la pròpia espècie.

Com és prou sabut, les proteïnes, juntament amb els glúcids i els lípids, són els elements fonamentals de la dieta humana. Normalment, la font principal de les proteïnes ha estat sempre de tipus animal. És per això que l'home caçador, ja sigui d'insectes o de grans peces, ha estat sempre a l'origen de totes les cultures.

Actualment la major part de les proteïnes animals són, en una gran majoria, produïdes amb mètodes sovint poc més o manco industrials, la qual cosa facilita l'accés, sense un cost excessivament elevat, a una gran majoria de la població. Això no sempre ha estat igual. En temps passat, i encara avui en societats no massa desenvolupades o com a mostra d'exotisme culinari, es consumeixen o s'han consumit tota casta de fonts proteíniques (Ramos \& Conconi 1988: 100-07). Exposarem alguns exemples d'aquest consum, referits sobretot a Mallorca.

Hem de distingir dos models fonamentals de consum alimentari: un més característic de l'àrea rural i un altre més propi de la urbana. Ambdós es poden identificar també amb els models de societat preindustrial i societat industrialitzada, encara que les dues classificacions siguin exces- sivament simplistes. En el model rural el menjar està relacionat fonamentalment amb la facilitat d'obtenció d'un recurs, sense que existeixin gaires més raons per a la selecció dels aliments. És un model de dieta 'natural' i el menjar està en harmonia amb el medi ambient dels voltants i els cicles de la naturalesa. En el model urbà hi ha molta més diversitat, sobretot a causa de la major varietat de l'oferta alimentària, de les nombroses tendències culturals que hi coexisteixen, i de les diferents procedències dels habitants de la ciutat. Cada un dels grups que la formen tenen les seves tradicions culinàries concretes, tributàries d'uns hàbits alimentaris propis. Ara bé, la pervivència de les maneres respectives d'entendre la cuina i l'alimentació no exclou una tendència a la uniformització, sempre que ho permeti el mercat de queviures.

\section{Les categories dels aliments}

L'escala de valoració d'un aliment no sempre coincideix en totes les cultures; mentre que determinats aliments són perfectament acceptats en certs models culturals, en altres, ben propers i amb trajectòries semblants, els mateixos productes són rebutjats per complet. Això pareix respondre al fet que l'elecció d'aliments per part dels humans depèn sobretot de sistemes culturals alimentaris (Fischler 1990: 32). Es podria invocar una qüestió de paladar, però el cert és que si traslladem els membres d'una cultura a un altre entorn, es repeteixen, sempre que és possible, les mateixes pràctiques culinàries o amb ben poques modificacions.

Farem referència a tres animals que han de 


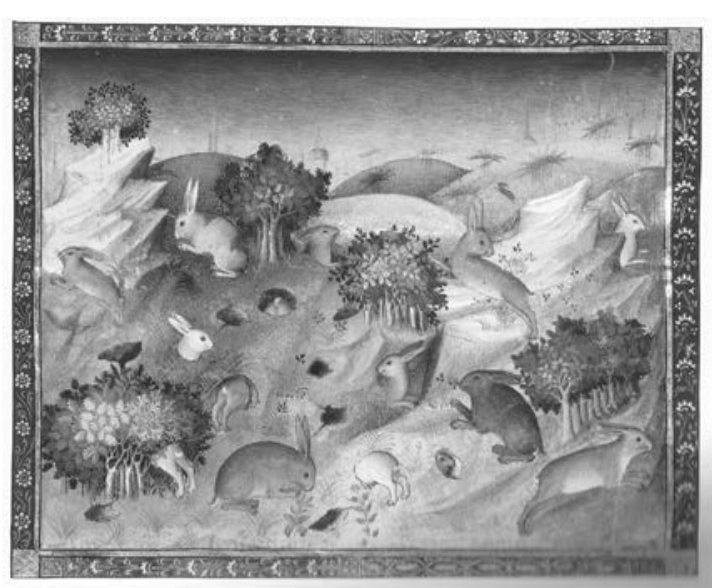

Un adagi popular recorda: Caçador fi, perdiu i coní. (Llibre de la caça de Gastó Febus. Bibliothèque Nationale de France, ms. fr. 616).

ser necessàriament capturats, ja que no han estat domesticats mai de forma continuada. Així doncs, responen a les característiques pròpies dels animals salvatges. Entre els animals de caça, fora dels de caça major, els més prestigiosos serien els que encara se segueixen caçant, com és ara el conill o la perdiu. (Aquesta valoració és parallela a la de determinades espècies marines, que seguint els corrents culturals, anirien guanyant o perdent consideració socioculinària. Un exemple d'això seria el cas de la llagosta, que era un dels articles més barats de la pedra del peix a l'Edat Mitjana. Als mercats de l'època, la llagosta es venia, segurament, per peces, a un preu que no consta al llistat de cotització dels peixos de 1361. Just es fa constar que es pagava un diner d'ajuda per peça si era petita o mitjancera i dos si era grossa. Segons això, era un dels productes que gravava un dels impostos més baixos de la venda del peix. Podem considerar, per tant, que era un aliment tengut en un nivell de valoració inferior als que havien de pagar xifres més elevades, com és ara l'emperador, que pagava dos sous i sis diners per lliura carnissera (1221 gr).

A finals del segle XIX començà a gaudir de certa consideració gastronòmica, segons les referències de l'Arxiduc Lluís Salvador (1956). Aquesta nova valoració comença a fer-se notar cap als anys setanta, moment en què la llagosta d'Alcúdia començava a ser exportada a Barce-

1. Així figurava als Capitols del peix de la parròquia de Pollença, de 1361 (Rotger Capllonch 1897-98: CXII). lona, on tenia un millor mercat. Entre els preus del peix de Mallorca donats per aquest autor, la llagosta queda situada en un nivell mitjà de cotització, encara que ja assenyala la importància de la seva captura (1956: 40). Actualment és considerada un dels símbols de la taula elitista. El cas contrari seria el de l'emperador. A Mallorca, passà d'ocupar el primer lloc en la llista de preus del peix de 1361 a una modesta segona línia en l'actualitat.

Al costat d'aquests hi hauria una altra categoria d'animals d'una valoració inferior i que sols es consumirien en entorns o societats determinades, caracteritzats pel seu fàcil accés. Aquests constituirien, per així anomenar-los, les proteïnes suplementàries o marginals, a les quals només es recorreria en moments d'escassesa i obeint a un model cultural concret.

La Mallorca de començaments de la segona meitat del segle passat mantenia, encara, un model alimentari molt proper al model rural. En aquest model, les fonts proteíniques habituals estarien fonamentades essencialment en els llegums, el peix o la carn, preferentment dels animals domèstics, i, ocasionalment, els obtinguts de la caça o pesca. Entre aquests animals salvatges, aquàtics o terrestres, que poden obtenir-se per captura, hi ha categories - no molt clarament explicades o justificades, però no per això manco reals. En aquesta distribució, en la qual solen tenir preferència les espècies més semblants a les domèstiques, podem veure-hi reflectides les peculiaritats gastronòmiques expressades en la cuina i l'alimentació, en tant que signe extern d'estament social.

Aquestes valoracions diverses depenen sobretot de l'evolució de l'escala socioculinària, en la qual intervenen diversos factors. Alguns tan distints entre si com poden ésser les tècniques de captura, l'abundància o escassesa de les preses a capturar, les normes dietètiques dictades per la religió o la normativa de salut vigent. A més, hi influeixen l'evolució experimentada pel paladar i les modes de cuinar pròpies de cada època. No entrarem a analitzar tot aquest cúmul de variants, les quals han condicionat i encara ara condicionen prou el consum de determinats aliments. 


\section{El prestigi variable de la tortuga}

Un exemple representatiu dels aliments que experimenten una estimació ambivalent en relació amb l'època i la cultura del seu entorn, seria el cas de la tortuga. Ara es considera un aliment selecte i de delicadesa notable, sobretot a la gastronomia angloamericana i a la de moltes regions de l'Extrem Orient, on compta amb una llarga tradició culinària i un prestigi considerable, que no sembla haver arribat mai a les nostres illes.

Alguns tractats de medicina àrabs recullen testimonis del seu antic consum, però no únicament com a aliment: la intenció terapèutica d'aquests escrits els fa considerar sobretot per les propietats com a recurs per tractar determinades patologies. Segons diu el famós farmacòleg malagueny Ibn Al Baytar (1197-1248), de les seves qualitats medicinals se'n troben ja valoracions al Kitab al agdiya ('Llibre dels aliments') d'Avenzoar (c. 1073-1162). ${ }^{2}$ Al Baytar assenyala que Avenzoar recomana el fetge dessecat i triturat amb mel per fer-ne un colliri per les cataractes. ${ }^{3}$ Molt més detallats i amplis resulten els dos capítols que el metge Abū Bakr Muhammad ibn Zakarīyā Rāzī (c. 865-c. 925), dit Razès, dedica a parlar de les tortugues (cap. 25 «Testudine», Razès 1544: 57980, i cap. 26 «De tortuca», 580), a l'apartat «De facultatibus partium animalibus», del seu famós Liber Almansorem, on descriu les aplicacions terapèutiques tant de la seva closca com de la carn.

Amb molta freqüència, doncs, les valoracions en els escrits mèdics tenen una intenció dietètica i terapèutica, detallant-ne principalment les qualitats de constitució, com es mengen i les indicacions que tenen com a remei medicinal. Però no tots els autors de tractats dietètics d'aquesta època fan referència a les capacitats qualitatives que se li atribueixen, ja sigui com a aliment o com a medicina. No figuren, per exemple, al Regimen Sanitatis Salernitanum o al De ferculis et condimentis de Giambonino de Cremona.

2. Cal afegir, però, que al Kitab al agdiya no hi ha cap esment de la tortuga.

3. «Tortue». Vegeu Leclerc (1877). La cita prové de la reedició (s. d.: 279).
Són objecte de l'atenció del metge Michele Savonarola, que en parla al Libretto de tutte le cosse che se magnano (c. 1450-52). Aquest text d'orientació preferentment dietètica, pertanyent al gènere dels regimina sanitatis, refereix que la carn de tortuga de terra és de digestió difícil, ja que és poc calenta i seca, encara que té alguna humiditat supèrflua. Menjar-ne, diu, genera melancolia i perjudica la vista, i si algú es posa sang de tortuga als ulls es tornarà cec, maldament es banyi en l'aigua on s'ha cuita. En canvi, aquesta mateixa sang, colada i beguda, és molt bona per a l'epilèpsia (morbo caduco). En aquest escrit s'hi troben ja instruccions per poder aguisar-la en vistes a la seva ingesta, ja no sols com a indicació d'un producte farmacològic, sinó orientant-la com a producte alimentari. Per menjar-ne, ha de ser esmocada, rentada amb dues aigües i una amb vi bo i vinagre. En tallarem el cap, la coa i les cames, bullint-la amb aigua, vi, vinagre i un poc d'all. Es condimentarà amb pebre negre, clau i menta. Adverteix que les de riu són perilloses i verinoses, essent més bones les de terra. De tota manera, considera que cap de les dues varietats són un menjar adequat per Borso d'Este, senyor de Florència i a qui anaven dirigits els seus consells (Nysted 1988: 137).

\section{De la medicina a la cuina}

Podem trobar altres consideracions sobre el seu valor medicinal i maneres de cuinar-les a obres de la mateixa família, com és el De honesta voluptate et valetudine, de Bartomeu Sacchi dit Platina (Sacchi 1475). Aquesta obra, publicada el 1475, estava present a algunes biblioteques de Mallorca des de finals de l'Edat Mitjana i fins ben entrat el segle XVII (Contreras Mas 1996). Hi figuren dos capítols sobre la tortuga, on es valora la seva carn com a producte medicinal i es donen instruccions per aguisar-la en vistes al seu consum: se li haurà de llevar cap, peus i butzes, s'ha de bullir i condimentar-la seguidament amb pebre negre, safrà i vermells d'ous mesclats en verjús (suc de raïms verds). A més d'aquesta composició, que seria, diríem, la més habitual, Platina fa constar 
que alguns la mengen amb allada o altres salses. ${ }^{4}$

Un llibre de cuina antic, un poc més tardà, que també dóna instruccions per cuinar tortugues, tant de mar com de terra o aigua dolça, és el del cuiner papal Bartolomeo Scappi (c. 1500-c. 1577). A l'Opera dell'arte del cucinare (Scappi 1570) informa de les temporades per menjar tortugues, segons siguin de mar, d'aigua dolça o de terra, així com les maneres de cuinar-les. Per a la tortuga marina recomana anar alerta a no rompre la bossa de la fel en escorxar-la i bullir-ne la carn, que prepara amb els mateixos ingredients que Platina, i diu que també se'n poden fer panades. Considera que les tortugues de terra són millors que les d'aigua dolça i que la femella és millor que el mascle. Indica que per matar-la li poden tallar

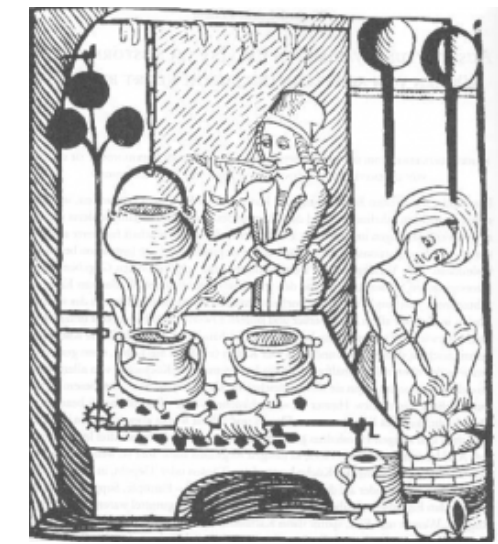

Una cuina medieval en un gravat del segle $X v$.

el cap i fer-li donar la sang, però que és millor ferho posant-la dins una olla d'aigua bullent. Llavors es submergeix en aigua freda i, llevant-li la closca, se separen els ous i el fetge, sense la bossa de la fel. Es poden fer frits amb jueverd, suc de taronja agra, sal i pebre bo. Amb aquesta mescla també es pot preparar la carn, però també es pot servir amb altres condiments. ${ }^{5}$ L'obra d'Scappi influí de-

4. Citam per la versió francesa Le platine en François (2003: 95; «De la tortue») i (2003: 169-70; «De la tortue et comment s'apreste»).

5. Citam per la versió castellana d'Scappi (2004: 37476): «Capítulo CLXV: De la talla y temporada de la tortuga de mar »; «Capítulo CLXVI: distintas maneras de guisar tortugas de mar»; "Capítulo CLXVII: De la talla y de la temporada de la tortuga de tierra y de agua dulce»; "Capítulo CLXVIII: Distintas maneras de guisar tortugas». cisivament la de Diego Granado Maldonado, que en reproduí les receptes i comentaris al seu Libro del arte de cocina (1611). ${ }^{6}$

Un testimoni de la presència de plats de tortuga a la cuina francesa antiga, el proporciona l'obra de François Pierre de La Varenne (16181678) Le cuisinier François, publicada el 1651. N'hi inclou un de «Potage de Tortuës», on prescriu llevar a la tortuga cap i peus i bullir-la amb aigua. En ser prop de cuita, cal afegir-hi vi blanc, herbes i llard. En acabar de coure, es lleva la closca i la part amarga (greix). Un cop feta a trossos, es fregeix adobant-la amb espàrrecs, brou i llimona. Una altra recepta proposa que, una vegada cuites de manera semblant, es fregeixin amb mantega o llard, jueverd i ceba, s'hi afegeixi un poc de brou i es lligui tot amb un vermell d'ou i verjús. Esmenta també una preparació en ragoust?

Aquesta tradició culinària francesa podria haver-se transmès directament a las cuines angleses o a les seves hereves del Nou Món, d'on es creu que procedeix el plat que més fama ha assolit a les grans cuines posteriors. Es tracta de la sopa de tortuga o «turtle soup», plat molt característic del model culinari angloamericà, on encara hi perviu. Es creu que començà a incorporar-se a la cuina anglesa a partir del segle XVII, procedent possiblement dels francesos o els espanyols installats al continent americà, que ja en menjaven els segles XVI i XVII. També se I'ha suposada procedent de les cuines dels esclaus negres de les Illes Barbados, a qui se'ls proporcionava carn de tortuga en substitució de la carn de bou, que era més cotitzada. Cap a 1711 la sopa de tortuga ja va servir-se a un banquet municipal de Londres (Gourou 1964), mentre que la seva fórmula es codificà per primera vegada el 1721 (Vitaux 2010). Bona part de la seva divulgació es deu a Hannah Glasse (1708-1770), autora del The Art of Cookery made Plain and Easy. Aquest imponent manual de cuina va ser publicat per primera vegada el 1747 i reeditat una vintena de vegades durant el set-

6. Granado Maldonado (1599). A l'edició d'aquesta obra feta a Lleida (1991), podeu veure aquests comentaris a les pp. 226-28.

7. Vegeu-les al facsímil modern La Varenne (2001): «Potage de tortue» 17; «Tortues» 113-14 i «Tortues en ragoust» 239. 


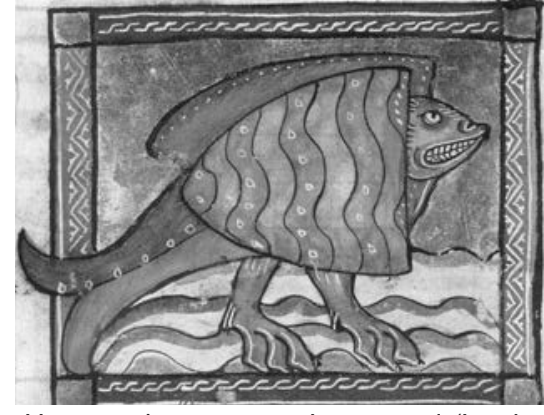

Tortuga. Honorius Augustinensis, Imago mundi (Londres, British Library, ms. Royal 12 C xIX).

cents i fins al 1843. A les taules londinenques, la posà de moda el restaurant The Ship and Turtle Tavern, de George Painter, on podien preparar un menú complet només de tortuga. Es proveïen de tortugues que feien arribar vives i les conservaven en grans peixeres installades als soterranis de l'establiment. També disposaven de carn de tortuga seca. El prestigi i preu del plat propiciaren la creació de la «Mock turtle soup» ('falsa sopa de tortuga') feta amb cap de boví. Va ser concebuda al segle XVIII com una imitació barata de la vertadera sopa de tortuga, si bé la seva recepta no aparegué a un llibre de cuina fins al 1808 (Vitaux 2010).

Els plats que es cuinen amb tortuga a terres catalanes tenen poc a veure amb aquesta tradició. Una primera recepta per cuinar tortuga en aquest entorn podem veure-la codificada al manual dels cuiners carmelites, escrit per fra Francesc del Santíssim Sagrament (1753-1824). A les seves planes s'indica que la tortuga s'ha de fer a trossos i bullir-la, mudant-li l'aigua dues o tres vegades per llevar-li el greix. La carn se sofregirà amb oli i ceba, afegint-hi una salsa de pinyons. Una vegada cuita, es condimenta amb safrà i espècies i es lliga el conjunt amb farina i vermells d'ou dissolts en el brou. La sang es fregeix i s'adoba amb un suc de perdiu i alls i agràs. ${ }^{8}$ La influència d'aquesta recepta és notòria en la La cuynera catalana, que la reprodueix quasi al peu de la lletra. Aquest conjunt de receptes, començat a publicar el 1835, en parlar de la tortuga assenyala que es ven a trossos per mor de les seves dimensions.

8. Vegeu la recepta «De la tortuga» d'aquest receptari de cuina conventual del segle XVIII (Santíssim Sagrament 2004: 240).
La proposta és fer-la en tallades petites, que se sofregeixen amb un poc d'oli i ceba. S'hi afegeix una salsa d'ametlles i avellanes, es lliga el conjunt amb farina i vermell d'ou i es condimenta amb safrà i espècies. Hi poden afegir la sang. $\bigcirc$ bé ferla fregir amb oli, fent-la amb la salsa dita «such de perdiu» (La cuynera catalana 1894, quadern III, 32), que és una beixamel condimentada amb pebre negre i suc de taronja o llimona. ${ }^{9}$

Una acurada i precisa informació sobre les formes de preparar-la, vigents a les cuines europees del segle XIX, són al Grand Dictionnaire de cuisine, monumental obra d'Alexandre Dumas i Denis-Joseph Vuillemot, publicada el 1873. Les informacions que s'hi donen són proporcionades als autors per $M$. Duclerez, antic cap de cuina de la casa Rothschild. Comencen comentant que a Nord-amèrica la tortuga és relativament abundant i es ven a un preu accessible a tothom, preparant-se de diverses maneres, però amb molta senzillesa. En canvi, diuen, a Anglaterra és molt estimada, i se'n fa un gran consum, encara que només es destina a fer-ne sopa. Concreten que les parts més delicades són les més gelatinoses, les aletes i els trossos més carnosos que estan dins la closca. Hi ofereixen la recepta de la «soupe à la tortue a l'Anglaise et a l'Americaine». Per a la seva preparació recomanen que la tortuga sigui fresca, especificant de manera molt detallada la manera de sacrificar-la i esquarterar-la, així com quines són les parts no comestibles, que s'han de llevar. Ho tornen a repetir més envant a la «Preparation de la tortue». Refereixen també les formulacions d'un «Potage à la tortue», molt semblant a la sopa de tortuga ja esmentada i la manera de fer les «Nageoires ('aletes') de tortue à la regence». ${ }^{10}$

Sols uns anys més envant trobam receptes

9. La cuynera catalana (1894, quadern III, 26) diu «such de perdiu y serà de aquesta manera: se posarà farina á sofregir ab oli remenantla de continuo, y en ser rossa se hi possará pebre y such de llimona ó taronja ó altre agre, y se deixatará, anyadint hi si es necesari un poch de aygua, se tirará ab lo peix en la cassola y se li fará donar algun bull, $y$ en estar assahonat se podrà servir».

10. Vegeu les diverses receptes a Dumas \& Vuillemot (1995: 145-46 i 174-76). 
semblants en una publicació espanyola, nascuda amb una pretensió equivalent. Es tracta de l'obra d'Ángel Muro Goiri, titulada Diccionario general de cocina (1892). A les seves planes s'hi recullen tant la vertadera sopa de tortuga com dues receptes de la imitació.11 Una altra obra del mateix autor, on figuren instruccions semblants per aquests plats, és al receptari titulat El practicón: tratado completo de cocina al alcance de todos y aprovechamiento de sobras. La seva primera edició coneguda és la de 1894, però fins als anys trenta del segle $x x$ va ser el tractat culinari més consultat i utilitzat pels cuiners espanyols. Ens assabenta que les millors tortugues per cuinar

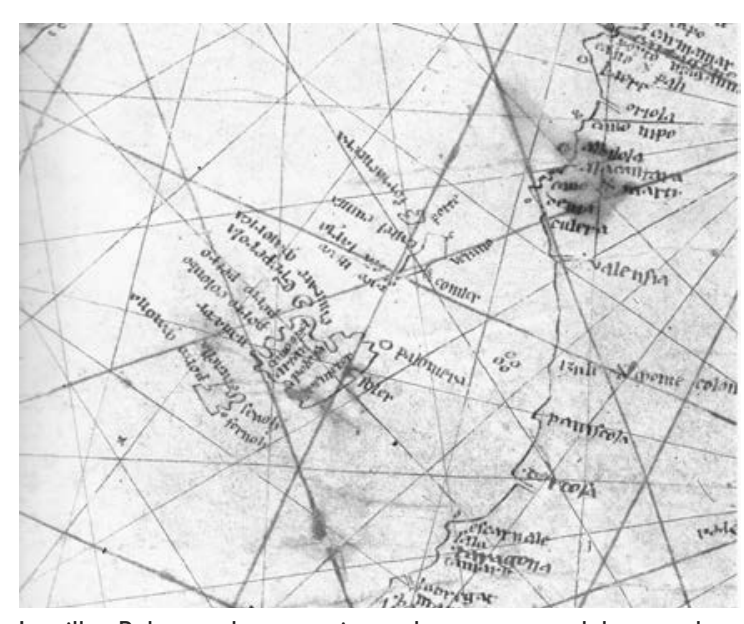

Les illes Balears a la carta pisana de c. 1290, un dels portolans occidentals més antics que es coneix, on es detallen els ports marítims més importants (París, BNF, Rés. Ge B 1118). ga i dues per la tortuga americana dita terrapine (Malaclemys terrapin), coneguda també com dors de diamant. Per a aquesta darrera, indica com preparar-la a la manera de Maryland i segons la moda en aquells moments del famós restaurant novaiorquès Delmonico (Bardají 1993: 320-21).

De fet aquestes dues receptes són publicades uns anys abans pel gran mestre Auguste Escoffier a Le guide culinaire, imprès per primera vegada el 1903 i reeditat el 1907, el $1912 \mathrm{i}$ el 1921. Aquesta obra es refereix a les receptes per cuinar la tortuga americana anomenada dors de diamant. Diu que a Europa és poc corrent que arribin vives, per la qual cosa solen usar-se conservades. La descripció i les receptes que proporciona són inspirades i basades en les del llibre The Epicurean (1894), del xef americà C. Ranhoffer, que va ser durant molt temps cap de les cuines de l'esmentat restaurant Delmonico de Nova York. A més de la recepta per cuinar-les «a la manera de Maryland» n'afegeix una altra «a la manera de Baltimore» i dues més per cuinar les aletes «a l'americana» i «al Madeira» (Escoffier 1990: 471-72).

Hem illustrat, doncs, amb el cas de la tortuga els principis que havíem desgranat abans amb la intervenció de diversos factors, que van des de les tècniques i condicions de captura, als dictats dietètics per raons religioses o higièniques, així com l'evolució del gust i la moda culinària.

\section{Cuinar tortugues, eriçons i rates de s'Albufera}

Malgrat el pes i la importància de la tradició en terres europees de la cuina de la tortuga de mar, no pareix haver influït gaire en les maneres de guisar-les a les Balears. A més d'algunes formulacions inèdites $\mathrm{i}$ en curs d'oblit, oferim algunes 
receptes de les Balears per preparar determinats animals salvatges, de la categoria dels considerats marginals i rarament consumits de forma quotidiana per la població en general. Són diferents maneres de preparar l'eriçó, la tortuga de terra o les rates de s'Albufera, ${ }^{12}$ animals presents únicament, i tal vegada ni això, pel fet de ser espècies protegides, a las taules d'una mínima part de la població. Així i tot, encara ara es conserva la memòria dels antics usos alimentaris d'aquests animals, però només com una raresa gastronòmica de temps passats. No sembla existir-ne consum actual i, si n'hi ha, es fa exclusivament als entorns familiars o d'amistat més estrictes i discrets, degut a la protecció dispensada a totes aquestes espècies, que ara conten amb rigoroses prohibicions legals de la seva captura.13

Cada una d'elles constitueix una mostra supervivent de les poques i rares restes d'un model alimentari relativament diversificat. Aquest model va ser substituït per una alimentació més uniformitzada i fonamentada en les proteïnes d'obtenció industrialitzada. Són testimonis d'un hàbit alimentari avui ja extingit o en indubtables vies d'extinció, per esgotament de les espècies consumides, totes protegides.

Les receptes culinàries que podeu veure als requadres procedeixen de receptaris antics 0 de manifestacions orals fetes per gent que les ha vist cuinar o que encara les ha cuinades. Els animals que s'aguien en aquestes receptes són tots animals no domèstics i constituïren una font addicional o marginal de les proteïnes ordinàries de la dieta normal. Aquestes proteïnes alternatives haurien d'ésser suposadament consumides sobretot pels nivells més baixos de la població, als quals altrament se suposa un escàs poder adquisitiu per poder accedir a proteïnes suficients.

12. Les rates arrosseres o de s'Albufera són en realitat lagòpodes (Arvicola campestris).

13. Amengual (1992: 29 i 34): hi són, per exemple, les sis varietats de tortugues que poden trobar-se a Mallorca; tres marines, dues terrestres i una d'aigua dolça i l'eriçó (Atelerix algirus).

\section{Tortugues}

Hem vist com la sopa de tortuga era un plat molt prestigiós a la gran cuina europea, mentre que no pareix haver-ho estat tant a la nostra cuina de diari. El consum de tortuga marina i de terra era ja relativament habitual a determinats entorns socials de la Mallorca del segles XVIII i XIX. Uns dels seus consumidors habituals eren els cartoixans del monestir de Valldemossa. Aquests monjos, que practiquen l'abstinència de carn durant tot l'any, poden menjar peixos en certes temporades. Com que fins al segle XIX no es pogué determinar si les tortugues eren peixos 0 animals terrestres, estaven autoritzats a menjar-ne. Amb aquesta finalitat les criaven a un recinte anomenat «hort de les tortugues», que encara es conserva (Ripoll Arbós 1978: 30, 34 i 95). Una estructura semblant i amb la mateixa finalitat és descrita per Eugeni Perea Simón al monestir de Santa Maria d'Escaladei, al Priorat (Perea Simón 1994: 35).

Coneixem dues receptes del segle XVIII per aguiar tortuga marina procedents d'un text de cuina de Menorca. Figuren al llibre de cuina conventual del franciscà fra Francesc Roger (m. 1764), titulat Art de la cuyna. Llibre ben discorragut y aprobat per a defensarme de los contraris, compost per fra Francesch Roger, religiós de obediencia de N.P.S. Francesch e morador en el Real Convent de CiutadeIIa. Està datat entre final del s. XVII i principis del s. XIX. Una és «Per fer pilotes de tortuga» i l'altre

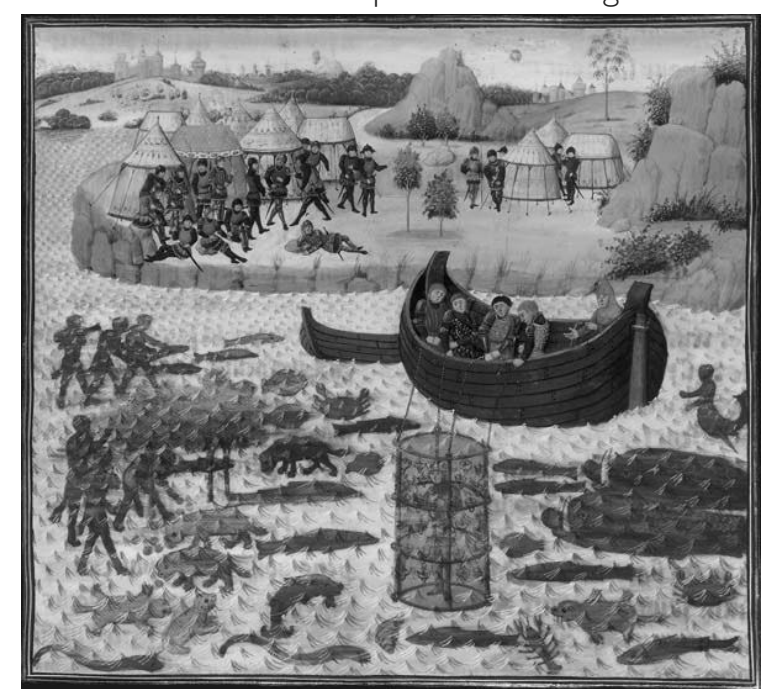

Alexandre Magne sota l'aigua (París, BNF, ms. fr. 9342). 
«Un plat de tortuga de la mar viva ab cassola» (Roger 1993: 181). Podem trobar-ne una altra en un dels manuscrits del seu coetani mallorquí l'agustí fra Jaume Martí. Val la pena fer notar que no tots els manuscrits que reprodueixen aquesta recopilació tenen el mateix contingut, com en el cas de la tortuga. El manuscrit més antic del recull esmentat, siglat $A$, no inclou cap recepta de tortuga, en canvi n'hi ha una en el manuscrit $D$, que és la que publicam.

La sang de la tortuga era un producte de consum habitual entre les classes més modestes de Palma cap a finals del segle XIX. Així ho reflecteix una de les narracions costumistes de Gabriel Maura i Montaner publicades entre 1879 i 1887 a les revistes locals La Ignorància i Sa Roqueta, vuit de les quals foren aplegades en el llibre Aigoforts (1892). Una d'elles, titulada «Un homo de ca seua» conta com una porció de sang de tortuga és adquirida al mercat del peix pel personatge central, que tot seguit se la menja frita per berenar al dematí (Maura 1920: 45).

Un altre llibre de cuina menorquí, on també es torna a recollir una adaptació de les recep-

\section{Greixera de tortuga}

Transcripció de l'obra de fra Jaume Martí (1989: 197). La mateixa recepta ha estat reproduïda per Ripoll Arbós (1984: 125-26). A la transcripció s'ha conservat l'ortografia del text de fra Jaume Martí.

Se los taye es cap y, penjada, s'escola la sanen de la que ab sos budells se poden fer butiferrons, 10 mateix que si fos sanch de porch, o se menja sofregida ab grells, lo mateix que sanch de moltó. De la tortuga se fa trossos y se passa per aigo bullenta 3 04 vegades per llevarli es gust de marina; $y$ ab un guinavet se li lleva tot el greix (el que es negre y no es blan).

Se sofregeix ab oli o sahim, se li afegeix aigo corresponent, y en ésser mes de mitx cuita se li possen ciurons tenres, pèsols, y dames fruita corrent, herbasana, moraduix etc., espícies, y lo dames propi de una graxera. Altres en lloch de aigo hey posen brou de jarret, y s millor.

Se closca de damunt de la tortuga no serveix mes que per sabó, etc. però se de devall se fa trossos, y se menja com lo demés de la tortuga.

De la carn de la tortuga se poden fer sobressades. tes de tortuga ja esmentades, és el De re cibaria. Aquesta obra de Pere Ballester, publicada el 1923 per primera vegada i profusament reeditada més envant, recull com es feien llavors les pilotes de tortuga (Ballester 1985: 98). Els ingredients i les maniobres per elaborar-les resulten molt semblants a les que ja explicava fra Francesc Roger més de dos segles i mig abans. Al quadre reproduïm la manera eivissenca de cuinar-la fins no fa gaires anys. Jaume Fàbrega, a les planes del Receptari exòtic assenyala l'existència d'una fórmula per fer «Tortuga amb all i pebre» vigent a Eivissa i Mallorca (Fàbrega 1997: 170). No en cita la procedència i la manera de preparar-les, amb all i pebre, és poc, o gens, corrent a la cuina mallorquina marinera. No és així a l'eivissenca, més influïda per la llevantina, per la qual cosa aquesta preparació segurament és pròpia d'aquesta darrera illa, on pogué ser importada des d'aquestes terres. Dues maneres de preparar-les fins no fa gaire a Mallorca s'inclouen a Memòria de la cuina mallorquina. Una és un «Aguiat de tortuga de terra», procedent de Colònia de Sant Pere, que presenta una metodologia molt semblant a la seguida per cuinar la de mar. La segona són unes «Sopes de tortuga de mar», recollida a Porto Cristo, de la qual es fa constar que es preparava el Divendres Sant. Les sopes que se n'escaldaven podien ser seques o brouoses, segons el gust. ${ }^{14}$

De tortugues en comprava i menjava tothom que en sabia cuinar, encara que el seu consum, com hem dit abans, estava limitat a gent d'arrels marineres, però hi havia altres factors que restringien, encara més, el seu consum habitual. ${ }^{15}$ El seu notable volum material era un obstacle a I'hora d'adquirir-les, per això solien ésser compartides entre un parell de famílies. Un altre entrebanc era la tasca de fer-la neta, que, com veureu, es fa amb sal i a força d'escaldar-la amb aigua tres o quatre vegades fins eliminar tot el greix de

14. Tugores (2005: 28 i 183): «Sopes de tortuga de mar» $\mathrm{i}$ «Aguiat de tortuga de terra».

15. La majoria de les informacions de caire antropològic sobre cuinar tortugues que aquí figuren, ens han estat proporcionades per la mare de na Pepita Cardona, na Maria Cardona de Can Pau, referint-les a Eivissa. Bona part de les mateixes, si no totes, creïm que són extensives a Mallorca. 


\section{Guisat de tortuga}

Recepta Eivissenca. Transcripció de l'obra de Ripoll Arbós (1984: 124-25).

Se fa neta, com ja s'ha dit la carn de la tortuga, cuidant de llevar be el greix negre, ja que de deixar-lo donaria a l'aguiat un gust agre desagradable. Una vegada llevat, se frega amb sal tros per tros i es comprova que ha quedat neta.

Se talla en trossos no molt grossos i se posa a sofregir, amb oli, en una greixonera. S'hi posen un parell d'alls, pèsols tenres, carxofes, ceba, tomàtiga i un poc de julivert, tot picat molt menut. S'hi poden afegir un poc de sobrassada o ventresca. Quant tot està sofregit s'afegeix aigua per coure-ho, patatons i pebre vermell.

En el murter se fa una picada amb pa fregit, ametles torrades $i$ alls torrats, una nyora frita i dos o tres vermells d'ou bullit. Una vegada ben picat es recull amb una mica de brou, afegint-ho a l'aguiat.

Se condimentarà també amb nou moscada, pebre negre, safrà i sal, deixant- ho coure fins que el brou hagi minvat la meitat i sigui cuit.

color blavós obscur, que donaria mal gust a tot l'aguiat. Aquest greix es torna blau quan s'escalda i ha d'ésser retirat a tall de ganivet. Això darrer representa per a la madona de la casa, segons paraules textuals de la persona que ens ha proporcionat la segona recepta eivissenca, «un matí de feina». El seu consum estava, per tant, limitat per factors de caire més aviat domèstic, però no per això manco importants.

Tot i això els aguiats de tortuga eren un dels plats més apreciats. Encara que no fossin un plat pròpiament de festa, el seu volum material i l'excepcionalitat de la seva captura suposava una bona raó per fer-ne un gran guisat, que representava una immillorable ocasió per compartir-lo amb els veïns i amics. Correntment es consumia a l'hivern: en temps de faves i pèsols, imprescindibles per al seu aguiat, però també en menjaven, en paella, el mes de juliol. La part més selecta de tot l'animal són els braços, ja que no tenen gens de greix i això els converteix en la part més fàcil de netejar i en la que aporta més garanties a l'hora de no agrejar el plat.

\section{Un altre guisat de tortuga}

Recepta eivissenca, proporcionada per na Maria Cardona de Can Pau.

Una vegada feta neta la tortuga de tot el greix blau obscur i groc, a força de escaldar-la i passar-la per sal es fa trossos. Han d'ésser d'un tamany mitjà, com a mandarines.

A dins una olla de test, començant amb oli fred, se sofregeixen primer dues nyores durant dos o tres minuts. Quant canvia de color, passant de vermell a granat, se retira la nyora i se posen els trossos de tortuga, que es sofregeixen.

Es deixa sofregir i quant la tortuga esta sofregida, s'afegeix una picada feta en es murter de les nyores sofregides, julivert, alls i tomàtiga pelada. Es fa una salsa amb tot això, que es deixa coure a poc foc, fins que sa tomàtiga no faci suc.

Se tapa d'aigua, deixant-ho bullir, a poc foc, una estona i s'afegeix una segona picada, en la que hi entren ametlles fregides o ben torrades i picades, que s'han de posar en aquest moment, ja que de lo contrari no surten cuites, pa fregit, una grapadeta de pèsols i una fulla de llorer.

Se deixa coure a poc foc, durant una hora o hora i mitja, fins que es vegi que esta cuita. Això se coneix quant punyint-la amb sa forqueta se desfà.

En els darrers moments de la cocció, un quart més o manco abans de treure-la d'es foc, s'afegeix el fetge cruu a trossets $i$, més envant, un tros de sobrassada vella, que no es desfasa, fet trossets, i botifarra o botifarró, també a trossets.

Pot anar acompanyada de patató fregit.

\section{Rates de s'Albufera}

L'animal que colloquialment a Mallorca anomenam rates són en realitat lagòpodes (Arvicola campestris) varietat de l'espècie Arvicola amfibia que es troba també en el nord d'Espanya. A Sa Pobla i Muro (Mallorca) els diuen també topos. La seva nulla presència a entorns que no li siguin propis en fa un recurs desconegut fora d'aquestes comptades localitats. Aquest extrem els fa diferenciar dels altres dos animals de forma ben clara, ja que limita la presència del seu consum a 
unes zones concretes i restringides. A diferència de la tortuga marina, que pareix esser aprofitada sobretot dins d'ambients mariners o vinculats a la mar, el consum d'aquest animal pareix estar limitat, lògicament, a la gent dels pobles mallorquins dels voltants de s'Albufera. ${ }^{16}$ Es poden menjar tot l'any i és perillós menjar-ne quant a s'Albufera es posen verins o adobs a la terra, per a l'arròs. Es recomana, per això, menjar-ne precisament a l'hivern, perquè l'aigua és més abundant i corre més, i, per tant, és més neta. ${ }^{17}$

Aquesta limitació a zones concretes potser explica part de la seva absència en tractats mèdics o culinaris. Encara que Dioscòrides esmenta els ratolins de camp i les rates cellardes, ho fa sols des del punt de vista farmacològic. Algunes de les seves indicacions seran repetides per Rhazés, l'únic autor antic que anomena múrids com a producte destinat al consum humà. L'esmentat «De facultatibus partium animalibus» d'aquest darrer, descriu especialment els usos farmacològics de les rates comunes i dels jerbus. De les primeres assenyala, entre altres indicacions, que la seva carn rostida asseca les baves dels infants i elimina les berrugues, mentre que la carn dels segons es considera bona per mitigar el mal de ventre (Razès 1544: 582-83, cap. 32-3).

Quasi totes les receptes per aguiar-les procedeixen de la comarca dels voltants de s'Albufera de Mallorca, l'única on són accessibles amb relativa facilitat. Gairebé totes les receptes comencen amb un primer bull i després se sofregeixen o fregeixen. Una fórmula per cuinar-les així la publicà Lluís Ripoll a Cocina de las Baleares (1974: 108). Hi explica com, una vegada escorxades i netes de butzes, s'han de bullir, esquarterar, adobar amb sal i pebre negre, per fregir-les amb oli abundant. Un cop cuites, hi podem afegir alls, porros i tomàtiga en abundància i un parell de pebres ('pebrots') coents. S'acaben de coure a foc lent. També es poden consumir bullides i adobades amb oli, sal i pebre negre. Ocasional-

16. A Eivissa les rates de s'Albufera tenien una aplicació terapèutica i alimentària alhora: el seu brou era administrat als malalts de tos ferina o cucurutxa per calmar-los la tossina.

17. Informacions proporcionades per Pere Crespí, àlies Pixedis, de Sa Pobla. ment, es cuinen amb arròs, tal com es podria cuinar un conill. Al quadre hi trobareu una manera, vigent fins no fa gaire, per cuinar-les amb porros, segons el costum de Sa Pobla. Una altra recepta poblera molt semblant és la de «Rates de s'Albufera fregides», inclosa en l'esmentada Memòria de la cuina mallorquina d'Antoni Tugores (2005: 183). D'aquest mateix origen és la recepta per fer-les amb tomàtiga, que figura a l'enciclopèdia de la cuina catalana, obra de Jaume Fàbrega (1997: 173).

\section{Eriçons}

Alguns textos dietètics antics aporten comentaris sobre l'eriçó, si bé amb una intenció més farmacològica que alimentària, de manera semblant al cas de la tortuga. Dioscòrides, a l'edició del seu text comentat per Andrés Laguna el 1555, descriu tant l'eriçó marí com el de terra, esmentantlo més com a remei medicinal que com a recurs comestible. Considera que el marí és convenient per l'estómac, laxatiu i diürètic. Les cendres de la closca són aptes per tractar la sarna, les ferides brutes o les excrescències carnoses. Els terres-

\section{Frit de rates}

Recepta de Sa Pobla, proporcionada per en Pere Crespí, àlies Pixedis. Una fórmula de preparació semblant podeu trobar-la a Ripoll Arbós (1984: 108).

Una vegada escorxades i tallada sa cova, se bullen amb aigua i sal. Se fan trossos, a quarts poc més o manco i se sofregeixen en una pella, adobades de pebre bo i una fulla de llorer. Han de sofregir a poc a poc. Més envant s'afegeix un pebre coent vermell, o més, si agrada.

Se sofregeix, a dins una greixonera, molt de porro tallat menut i just sa part blanca, amb una cabeça d'alls esclafats. Quan es porro es quasi cuit, safegeix tomàtiga de ramellet pelada i tallada menuda. Sadoba de sal i pebre bo.

En ésser confitat es porro, s'afegeixen ses rates, ja sofregides, i se cou tot plegat, tapat i a poc foc. 
tres són indicats per a la caiguda del pèl, mal de ronyons, hidropesia, espasmes, lepra i caquèxia (Dioscòrides 1968: 123-24).

El «De facultatibus partium animalibus» de Rhazés parla extensament de les aplicacions terapèutiques de diverses parts dels eriçons, com són carn, fetge, sang, ulls o pell. Refereix, entre altres indicacions, que la carn de l'eriçó cuita o torrada és útil contra la lepra o per fer-ne emplastres per tractar els nirvis contrets i adolorits (Rhazés 1544: 578-79, cap. 23 De ericio). A la versió catalana del text d'Ibn Wafid, Llibre de les medicines particulars, es descriuen les possibilitats farmacològiques de l'eriçó. La seva carn cremada i feta cendres és indicada com a cicatritzador de ferides. Distingeix les propietats de l'eriçó terrestre, o salvatge, de les de l'eriçó marí. D'aquest darrer senyala que «es de bon menjar a l'estòmac, e ablaneix lo ventre e la sua çenra can es metuda als logars pelats fa y naxer los cabeyls y vede de córrer los honors en les entremeses» (Faraudo de Saint-Germain 1943: 169).

El sienès Ugo Benzi (1376-1439) explica que la carn de l'eriçó no genera gaire bons humors, però també té virtuts: conforta l'estómac, laxa el ventre i és útil per tractar la lepra, la ronya, la litiasi renal, els hidròpics, l'enuresi i les mossegades de cucs verinosos. Reconeix que no eren menjats pels antics, però que pelats, bullits amb un poc de vi, sal i vinagre, per llevar-los el gust de salvatgina, es poden rostir a l'ast adobats amb saïm i clau. En el comentari set-centista del text de Benzi, el bolonyès Baldasare Pissanelli recomana que per menjar-lo sigui jove, gras i consumit sobretot en temps molt freds. Es tendrà penjat a l'aire molt de temps, fins que la carn sigui tendre. Reconeix que és de digestió difícil i generador de molta flegma i melancolia. Recomana menjar-lo en pastís, adobat amb moltes espècies o bé rostit amb moltes herbes d'olor, canyella i all. ${ }^{18}$

En les paraules de Rhazés es fonamenta l'opinió sobre les seves vessants farmacològica i dietètica exposades per Michele de Savonarola al Li-

\footnotetext{
18. La primera edició del Tractato és feta a Milà per Pietro de Corneno el 1481. Citem per la reedició de 1620 (pp. 324-25).
}

bretto de tutte le cosse che se magnano, redactat a mitjan segle Xv (1988: 136). Considera que la seva carn és poc calenta i té poca humiditat, essent mala de pair. Menjar-ne produeix dificultats per orinar. Ara bé, val per les malalties pulmonars, en les quals s'usa secada i mesclada amb oximel. També és bona pel mal de ronyons. Per indicar el poder afrodisíac de la sang mesclada amb oli, Savonarola extreu les seves informacions de l'Almansorem de Rhazés, concretament del Tractat IV, «De propietatibus iuvamentis et nocumentis, sexaginta animalium, sermo 13» (segons indica Nysted 1988: 84). Qui s'unti el cos i la part femoral amb aquesta poció podrà tenir relacions sexuals amb qualsevol dona. La carn de l'eriçó de mar és millor de qualitat i perjudica manco l'estómac. Si es fa cuit i rostit, val pels tísics, els leprosos i els que tenen mal de costat. Aquesta darrera maniobra, que veurem a les receptes mallorquines, és una maniobra típica de la cuina medieval. La finalitat de sotmetre una carn a aquestes dues distintes coccions, a les quals se'ls atribuïen capacitats distintes per «despertar els valors» de la carn, tenia l'objectiu d'estimular-ne les seves característiques favorables. No deu ser casual que aquest doble processament sigui el mateix que segueixen les receptes mallorquines que han arribat fins avui.

El comentari del text esmentat de Dioscòrides, fet pel metge Andrés Laguna (1499-1559), és exclusivament orientat a les virtuts i indicacions medicinals dels eriçons terrestres. Sobre el de mar, comenta que la carn té un gust semblant a la tonyina o a l'anxova salades i que menjada crua és «un muy grande alcahuete del vino» (Dioscórides 1968: 123-24).

Una primera notícia del seu antic consum a Mallorca i arreu de totes les Balears la proporciona l'Arxiduc Lluís Salvador (1871). Al seu valuós Die Balearen ens fa saber que cap al darrer terç del segle XIX es consumien eriçons de terra cuinats amb arròs o fregits, formes molt semblants a les que hem recollit encara en els nostres dies. El mateix autor explica que el seu consum ja estava limitat generalment a la ruralia i que, degut a la seva escassesa, quasi mai eren consumits a la ciutat (Àustria 1985: 516). 


\section{«Principi de arissons»}

Transcripció de l'obra de fra Jaume Martí (1989: 166). Hem respectat l'ortografia del text original. La mateixa recepta ha estat reproduïda per Ripoll Arbós (1984: 332)

Per farcir los arissons, feràs el farciment de sèmola, ous, blanch i vermell, preba bo, sefrà y brou de moltó, ab una salseta de melles torrades que feràs después de farcits.

\section{Fideus d'eriçó}

M'ha proporcionat les dues receptes següents en Martí Santandreu

En pic que l'eriçó està net i decantades ses pues, se li lleva sa freixura i es cap, tallant-lo en quatre trossos. Se sofregeix tot plegat, afegint-hi ceba tallada menuda i, en ésser ben sofregida, tomàtiga de ramellet, també tallada menuda. En ésser tot ben sofregit s'afegeix aigua i se deixa bullir a poc foc, molt de temps, fins que sigui cuit, afegint s'aigua que serà mester.

Quant s'eriço és cuit, el treuen d'es brou i afegeixen es fideus. Els trossos d'eriçó se fregeixen i es poden servir amb patates fregides.

\section{Eriçó rostit}

Se prepara de la mateixa manera que per fer fideus. Se xapa, de per llarg, en dos trossos i se bull una bona estona, però sense que sigui massa cuit. Llavors se treu $i$ es posa a dins una rostidora, adobat amb oli, suc de llimona, pebre bo i sal. S'acaba de coure rostint-lo al forn.

Una recepta per cuinar-lo «amb tomàtics» figura al manual sobre cuina menorquina de Pedro Ballester (1985: 93). A Eivissa eren també plat habitual de la seva gastronomia antiga tradicional. Tres maneres de preparar-los segons l'antiga cuina pròpia d'aquesta illa, guisats, amb arròs i rostits, són descrites al llibre de Juan Castelló Guasch (1971: 107-08). Una altra recepta d'aquesta illa, és esmentada per Fàbrega (1997: 173), el qual descriu un mètode per cuinar-los embolicats amb argila. Fins no fa molts anys, a la zona de Sa Coma (Andratx) es menjaven en paella i també fent-ne un arròs brouós. Aquesta darrera preparació possiblement es tracti d'una variant que modifica l'hidrat de carbó bàsic del plat dels «fideus d'eriçó», la recepta dels quals figura al quadre. ${ }^{19}$ Altres receptes per cuinar eriçons de diferents maneres, procedents de distintes localitats de Mallorca, han estat recollides per Antoni Tugores. A Memòria de la cuina mallorquina hi esmenta dues maneres de fer-lo rostit, procedents d'Inca i Calonge, on, abans de rostir-lo, el bullen. Una el sofregeix posteriorment i llavors l'enforna, mentre que l'altra el rosteix directament després de bullir-lo. N'hi ha també dues d'eriçó fregit: una de procedència poblera feta amb porros, i l'altra manacorina que el cuina amb alls. Una darrera, recollida a Randa, el prepara sofregit. A totes, manco a la que el combina amb porros, l'adob es fa amb pebre bo i suc de llimona. ${ }^{20}$ Resulten significatives la varietat de procedències i les distintes maneres de cuinar-lo que n'exposa. El conjunt representa un testimoni ben significatiu de la difusió i acceptació que el consum d'aquest animal va tenir a Mallorca, al manco, fins a la primera part del passat segle $x \times$.

\section{Conclusions}

El consum de tortugues, rates de s'Albufera o eriçons devia ser una pràctica relativament estesa a l'època medieval, encara que els testimonis procedents d'obres de medicina es refereixen sobretot a les seves aplicacions com a remei farmacològic. Més envant, i des del renaixentistes, com passa amb tants d'altres productes (recordem per exemple les espècies), passaren de la farmacologia a la cuina. Això no significa que temps abans no es consumissin com a produc-

19. Així ens ho ha comunicat Jaume Bover, que recorda com son pare, cuiner de professió, feia un arròs amb eriçó, de les característiques esmentades.

20. Eriçó Rostit, Inca; eriçó rostit, Calonge; eriçó fregit amb porros, Sa Pobla; eriçó fregit amb alls, Manacor, i eriçons sofregits, Randa (Tugores 2005: 183). 
te alimentari, però els tractats culinaris d'època clàssica, com el d'Apici, no en fan cap esment.

La tècnica de confecció de les receptes presentades mostra trets característics de la cuina medieval. Com és ara la prebullició, el pas de la carn per aigua bullint abans de coure-la, de la tortuga. Altretant passa amb la seriació de les distintes coccions a què se sotmet la carn de l'eriçó i de les rates. El mateix podem pensar, si bé amb manco seguretat, de la varietat d'espècies que s'afegeixen als seus guisats. Hi podem advertir també altres característiques de la cuina antiga, com són la cocció a poc foc i la trituració dels elements complementaris del guisat.

Poden considerar-se, per tant, models reals de cuina arcaica que han conservat alguns dels seus trets inicials. Les modificacions que ha experimentat serien una conseqüència de l'evolució culinària i les preferències gustatives, a fi d'adaptar-se als gustos i tendències culinàries més modernes i d'aparició més recent. Així seria, per exemple, el cas dels «fideus d'eriçó», tal vegada fruit d'una adaptació de la preparació amb arròs, que sembla ser més antiga, segons la referència de l'Arxiduc Lluís Salvador.

Totes elles formen part de la nostra cuina més antiga, un dels aspectes més canviants del nostre patrimoni cultural. Hem tingut potser una de les darreres oportunitats per conservar aquests testimonis d'una forma de viure que, com les mateixes espècies cuinades, estan en camí d'ésser, i tal vegada ni ésser, tant sols història.

\section{Bibliografia citada}

Amengual, Josep, 1992: Les espècies protegides, Govern Balear: Conselleria d'Agricultura i Pesca.

ÀustriA, Luís Salvador de, 1985: Las Baleares por la palabra y el grabado. Mallorca (Parte General), Palma: Caja de Ahorros de Baleares [1a ed. Leipzig, 1871].

Àustria, Luís Salvador de, 1986: Las Baleares. La Pesca. Navegación y construcción de buques, Palma, p. 40 [aquesta obra es una reedició d'una part del Die Balearen in Wort und Bild, text imprès per primera vegada a Leipzig el 1871].

Ballester, Pedro, 1985: De re cibaria. Cocina pastelería, repostería menorquinas, pròleg de Ramon Cavaller Triay, Barcelona: Sintes (5a ed.).

BARDAJí, Teodoro, 1993: Indice culinario, Madrid, 1915 [ed. facsímil, Saragossa: La Val de Onsera].

Benzo, Ugo, 162o: Ugo Benzo, Regole della sanità et natura de' cibi [...], Domenico Tarino.
Castelló Guasch, Juan, 1971: Bon profit (El libro de la cocina ibicenca), Palma: Alfa.

Contreras Mas, Antoni, 1996: «La literatura culinària en la Mallorca baixmedieval», La Mediterrània, àrea de convergència de sistemes alimentaris (segles V-XVIII), XIV Jornades d'Estudis Històrics Locals, Palma: Institut d'Estudis Baleàrics, 729-34.

Dioscórides Anazarbeo, Pedacio, 1968 Acerca de la materia medicinal y de los venenos mortíferos, Traduzido de lengua grega, en la vulgar catellana [...], Anvers: Juan Latio, 1555 [ed. facsímil de l'edició de Salamanca: Matias Gast el 1566. Madrid: Instituto de España].

Dumas, Alexandre \& Denis-Joseph VUILLEMOT, 1995: Grand Dictionnaire de cuisine, Payré: Edit-France [1a ed. París: A. Lemerre, 1873].

Escoffier, Auguste, 1903: Le guide culinaire. Aide-mémoire de cuisine pratique, amb collaboració de Philéas Gilbert i Émile Fétu, París: Flammarion.

Escoffier, Auguste, 1990: Guida alla grande cucina. II maestro della cucina classica, Pàdua: Franco Muzzio.
FÀBREGA, Jaume, 1997: La cuina catalana, vol. 1: Història, productes i tècniques, Barcelona: L'Isard.

Faraudo de Saint-Germain, Luis, 1943: El «Libre de las medicines particulars» Versión catalana trescentista del texto árabe del «Tratado de los medicamentos simples») de Ibn Wafid, autor médico toledano del siglo XI, Barcelona: Real Academia de Buenas Letras.

FIsCHLER, Claude, 1990: L'homnivore: le goût, la cuisine et le corps, París: Odile Jacob.

GlASSE, Hannah, 1747: The Art of Cookery, made Plain and Easy [...], Londres: printed for the author; and sold at Mrs. Ashburn's, a China-Shop, Corner of Fleet-Ditch.

Gourou, Pierre, 1964: «L'homme et la tortue», L'Homme, 4.3, 110-17. http://www.persee.fr/web/revues/ home/prescript/article/hom_04394216_1964_num_4_3_366670

Granado Maldonado, Diego, 1599: Libro del arte de cozina, en el qual se contiene el modo de guisar de comer en qualquier tiempo [...], Madrid: Luis Sánchez. 
La cuynera catalana ó sia reglas útils, fácils, seguras y económicas per cuynar bé, 1894 [6a ed.], Sant Gervasi: Torras.

La VARenNe, François Pierre de, 2001: Le cuisinier francois: enseignant la maniere de bien apprester \& assaisonner toutes sortes de viandes [...], París: Chez Pierre David, 1651 [ed. facsímil, Houilles: Manucius].

LeCLeRC, L., 1877: «Traité des Simples par Ibn el-Beithar», Notices et Extraits des manuscrits de la Bibliothèque Nationale et autres bibliothèques, 23 [reedició feta per la Université de Lille III i l'Institut du Monde Arabe, París, s. d., vol. II].

Le Platine en François, De honesta voluptate et valetudine, d'après l'édition de 1505, Houilles: Manucius, 2003.

MARTí, Jaume, 1989: Receptari de cuina del segle XVIII, ed. Joan Miralles i Montserrat i Francesca Cantallops, Barcelona: PAM.

Maura i Montaner, Gabriel, 1920: Aigoforts, Barcelona.

Muro GoIrI, Ángel, 1892: Diccionario general de cocina ilustrado con cromos de lujo [...], II, Madrid: José María Faquineto.

MURO GoIRI, Ángel, 1982: El practicón: tratado completo de cocina al alcance de todos y aprovechamiento de sobras [...], Madrid: Miguel Guijarro, 1894 (4a ed.) [ed. facsímil, Madrid: Ediciones Poniente].
Nysted, Jane (ed.), 1988: Michele de Savonarola, Libretto de tutte le cosse che se magnano: un'opera di dietética del sec. xv, Estocolm: Almqvist \& Wiskell.

Perea Simón, Eugeni, 1994: Gastronomia divina, Barcelona: Destino.

Ramos, Julieta \& Elorduy de ConconI, 1988: «Los insectos como fuente de proteínas», Carencia alimentaria. Una perspectiva antropològica, Barcelona: Serbal-Unesco.

RANHOFER, Charles, 1894: The Epicurean. A Complete Treatise of Analytical and Practical Studies on the Culinary Art Including Table and Wine Service [...] Making a Franco-American Culinary Encyclopedia, Nova York: Charles Ranhofer.

RHAZÉs 1544: [Liber Almansorem], Basilea In officina Henrichi Petri.

Ripoll Arbós, Luis (ed.), 1984: Cocina de las Baleares, Palma.

Ripoll Arbós, Lluís, 1978: Sucinta historia de la Cartuja de Valldemossa, Palma: Mossèn Alcover.

Ripoll Arbós, Lluís, 1974: Cocina de las Baleares. Más de 500 recetas de Mallorca, Menorca e Ibiza, Palma: Mossèn Alcover (2a ed.).

Roger, Francesc, 1993: Art de la cuina. Llibre de cuina menorquina del segle XVIII, ed. Andreu Vidal Mascaró, Maó: Institut Menorquí d'Estudis.
Rotger Capllonch, Mateo, 1897-98: Historia de Pollensa, vol. I, Palma.

SACCHI, Bartolomeo, 1475: Platynae de honesta voluptate et valetudine, Venècia: Laurentius de Aquila et Sibyllinus Umber, 13 Juny 1475 [una altra edició dels mateixos anys és la romana de Udalricus Gallus (Ulrich Han), c. 1475].

Santíssim Sagrament, Francesc del, 2004: Instrucció breu i útil per los cuiners principiants segons lo estil dels carmelites descalços, ed. M. Mercè Gras i Agustí Borrell, Barcelona: PAM.

SCAPPI, Bartolomeo, 1570: Opera di m. Bartolomeo Scappi ... Divisa in sei libri [...], Venècia: Michele Tramezzino.

SCAPPI, Bartolomeo, 2004: Del arte de cocinar: obra del maestro Bartolomeo Scappi, cocinero privado del papa Pío $V$, trad. i notes de Raffaello Dal Col i Juan Luis Gutiérrez Granda, Gijón: Trea.

Tugores, Antoni, 2005: Memòria de la cuina mallorquina. Receptes antigues de tots els pobles, Palma: Documenta Balear.

VITAUX, Jean, 2010: «Vraie soupe à la tortue ou faux potage tête de veau ?», Histoire et gastronomie, http:// www.canalacademie.com/ida5243De-la-soupe-a-la-tortue-a-la-tete. html 